\title{
Perspectives of renal denervation from hypertension to heart failure in Asia
}

\author{
Kazuomi Kario ${ }^{1} \cdot$ Tzung-Dau Wang $^{2}$
}

Received: 30 June 2021 / Revised: 30 August 2021 / Accepted: 1 September 2021 / Published online: 15 October 2021

(c) The Japanese Society of Hypertension 2021

Hypertension is the most powerful risk factor of cardiovascular disease [1], and antihypertensive treatment significantly reduces the rate of atherosclerotic cardiovascular events and heart failure in patients with hypertension [2-4]. There are evidence of experiment studies which support the renal denervation $(\mathrm{RDN})$ is effective to reduce sympathetic activity and blood pressure (BP) [5]. Recently, evidence from several sham-controlled clinical trials of RDN in patients with hypertension with and without medication has been published [6-8]. The majority of these trials showed a significant reduction in $\mathrm{BP}$ after RDN, regardless of the device used. In this issue of Hypertension Research, longterm follow-up results from a real-world registry, Global SYMPLICITY Registry (GSR) Korea, have been published [9]. In addition, the meta-analysis and systematic review of recent sham-controlled clinical trials [10], including REQUIRE [11] and RADIANCE Trio [12] and the result of patient preference survey in Japan [13] have been released in this issue. Here, we discuss the clinical implication and perspectives of a RDN-based hypertension management strategy in Asia.

\section{Asian characteristics}

There are several important Asian characteristics of hypertension and its impact on cardiovascular disease [14, 15]. In Asians, the slope of the association between increasing BP and the risk of cardiovascular events is steeper than in

Kazuomi Kario

kkario@jichi.ac.jp

1 Division of Cardiovascular Medicine, Department of Medicine, Jichi Medical University School of Medicine, Tochigi, Japan

2 Cardiovascular Center and Divisions of Cardiology and Hospital Medicine, Department of Internal Medicine, National Taiwan University Hospital, Taipei City, Taiwan
Westerners [16]. Masked uncontrolled hypertension, defined as controlled office BP but uncontrolled home or ambulatory BP, occurs in $25 \%$ or more of medicated patients with hypertension [17]. Masked uncontrolled hypertension includes morning and nocturnal uncontrolled hypertension and is more frequent $(\approx 50 \%)$ in Asian populations [18], due at least in part to higher salt intake and higher salt sensitivity $[14,15]$. These hypertension phenotypes defined using out-of-office BP are associated with increased risk of stroke, myocardial infarction, and heart failure [17]. These data support recommendations that outof-office BP measurements should be used to guide the management of hypertension [2, 19].

\section{The Asia Renal Denervation Consortium}

The Asia Renal Denervation Consortium (ARDeC) consensus conference was recently convened to share up-todate information and regional perspectives on the scientific evidence for renal denervation, and recently released the consensus statement and perspectives on RDN in Asia [20]. The goal of the consortium was to achieve consensus recommendations on RDN that might help inform healthcare professionals in Asia. There is a good body of evidence on which such recommendations can be based, as summarized below.

\section{Symplicity HTN-J}

Was the first prospective randomized study to focus specifically on Asian patients with resistant hypertension [21, 22]. Differences in systolic BP (SBP) reductions from baseline after RDN of only the main renal artery using a first-generation radiofrequency catheter were not significantly different from those seen in the control group (who were receiving standard pharmacotherapy). Three-year follow-up data showed significant and marked reductions in office BP in patients treated with RDN, without significant procedural complications [22]. 
The lack of difference in BP reductions between the RDN and control groups in the primary analysis may have reflected a lack of statistical power due to early discontinuation of the trial. However, the magnitude of 24-h SBP reductions after RDN were similar to those achieved in the subsequent sham-controlled SPYRAL HTN OFF-MED, SPYRAL HTN ON-MED, and RADIANCE-HTN SOLO trials that utilized newer RDN system technology. Although patients from Japan were included in both SPYRAL HTN trials $[7,8]$, the numbers were too small to evaluate any ethnic differences in the BP-lowering effect of RDN.

Data from the SYMPLICITY HTN-J study showed that reductions in ambulatory BP after RDN occurred consistently over the 24-h period, including at nighttime and in the morning. Given that nighttime and early morning hypertension are associated with increased cardiovascular risk independent of office BP in Asian patients with hypertension [23-25], the clinical implications of RDN therapy could be important in Asian countries.

\section{Global SYMPLICITY Registry Korea}

Evidence for a greater effect of RDN on long-term SBP reductions in Asians versus Caucasians came from Global SYMPLICITY Registry (GSR) Korea 3-year follow-up. The overall GSR has enrolled over 2700 real-world patients and more than 2300 of these have now been followed for 3 years [26]. Data show that RDN was safe and was associated with significant reductions in office and 24-h BP up to 3 years of follow-up in multiple high-risk subpopulations including the elderly, and patients with diabetes mellitus, chronic kidney disease, isolated systolic hypertension, and arrhythmias [26]. Analysis of data from the GSR Korea
Registry showed that changes in office SBP from baseline to 6 months were similar in Koreans compared with Caucasians $(-19.4 \pm 17.2$ vs $-20.9 \pm 21.4 \mathrm{mmHg})$, but at the 12-month follow-up, SBP reductions were significantly greater in Koreans versus Caucasians $(-27.2 \pm 18.1$ vs $-20.1 \pm 23.9 \mathrm{mmHg} ; p=0.004)$ [27]. Data in this issue from the GSR Korea 3-year follow-up confirmed these differences [9].

\section{Global SYMPLICITY Registry Taiwan}

Another Asia-specific analysis of the GSR included patients enrolled from Taiwan $(n=26$, mean age $59.1 \pm 13.8$ years, baseline office SBP $168.2 \pm 19.8 \mathrm{mmHg}, 8$ treated with the Symplicity Flex catheter and 18 with the Symplicity Spyral catheter) [28]. Sustained reductions in office SBP were documented after RDN, for up to 3 years in the Symplicity Flex group and up to 2 years in the Symplicity Spyral group. In the Symplicity Flex group, office SBP reductions at 3 months and 3 years were $14.9 \pm 14.7$ and $29.7 \pm 25.9 \mathrm{mmHg}$, respectively (both $p<0.05$ vs baseline). Corresponding reductions in the Symplicity Spyral group were $21.2 \pm 28.7$ and $42.4 \pm 10.7$ mmHg, respectively (both $p<0.05$ vs baseline). Again, data suggest that RDN is a promising strategy for the management of hypertension in Asia.

\section{Comparative data}

Figure 1 summarizes changes from baseline in office and ambulatory SBP at 1 year after RDN in Asian patients with hypertension enrolled in the SYMPLICITY HTN-J study plus GSR Korea, Taiwan, Hong Kong, Malaysia, Singapore and Thailand, compared to other patients with hypertension

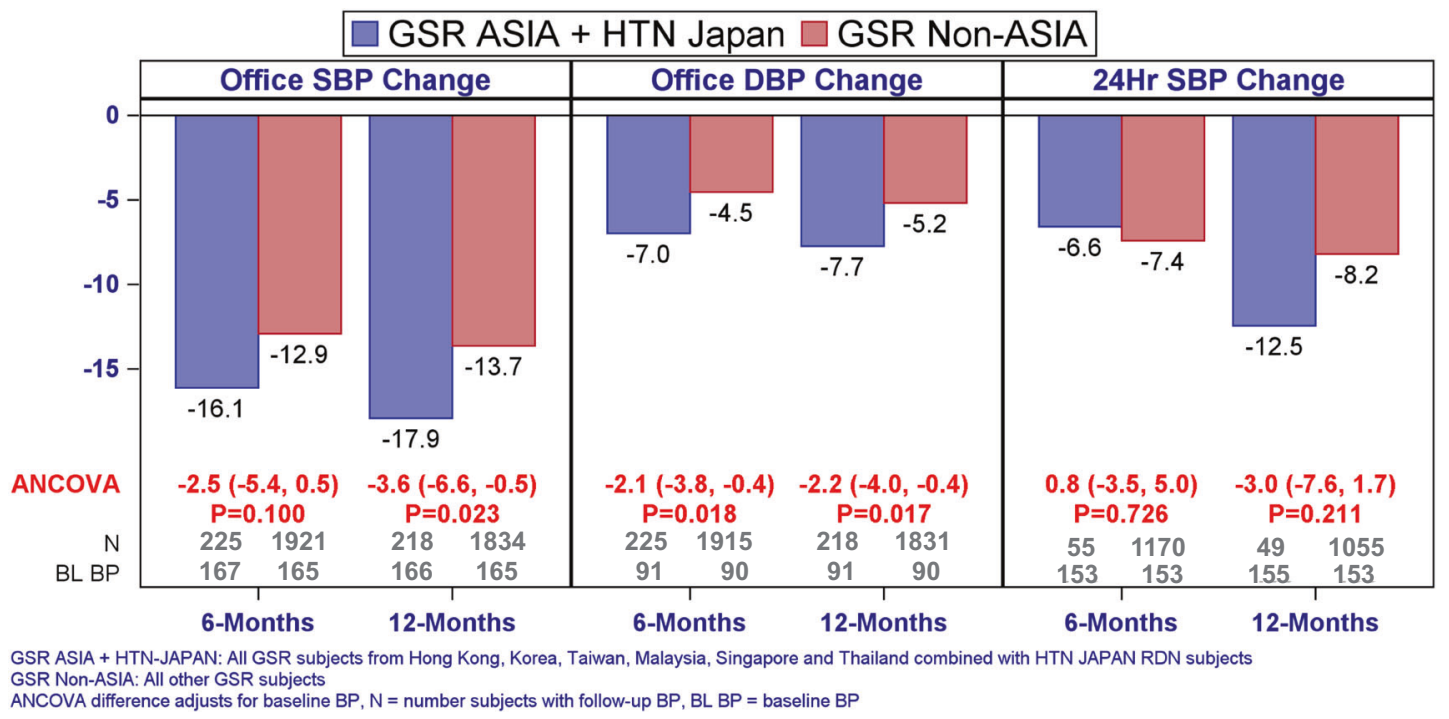

Fig. 1 Office blood pressure changes at 6- and 12-month follow-up in Asian versus Caucasian populations 
enrolled in the GSR. At 6 months after RDN, reductions in office and 24-h ambulatory SBP were comparable between the Asian and non-Asian patients. In contrast, reductions in office SBP at 12 months, and office diastolic BP at 6 and 12 months, were significantly greater in Asian versus non-Asian patients. In the SYMPLICITY HTN-J and GSR-Korea studies, office SBP decreased gradually over time, reaching stable reductions of $25-30 \mathrm{mmHg}$ compared with baseline. In contrast, the final reduction in office SBP achieved in the overall GSR was almost $15 \mathrm{mmHg}$, which is nearly half that seen in Asian patients, and maximum reductions were achieved by the 6-month follow-up with little change thereafter. Thus, based on the available data, the BP-lowering effects of RDN in Asian patients with salt-sensitive hypertension appear to be at least comparable to, or possibly greater than, those in patients with hypertension from other ethnic groups. However, additional prospective, controlled studies are needed to further evaluate and confirm differences in the BP-lowering effects of RDN in patients of Asian versus other ethnicity.

\section{RDN for "perfect" blood pressure control}

A key feature of the BP-lowering effects of RDN is that BP is reduced throughout the 24-h period, including nighttime and in the morning $[29,30]$. Most currently available antihypertensive medication is taken once daily in the morning. However, this is associated with a risk of weakening BP-lowering effects during nighttime and in the early morning prior to the next drug dose [31]. In contrast, available clinical trial data indicate that RDN effectively lowers 24-h BP, including both nighttime and morning BP, in patients with hypertension both in the presence and absence of antihypertensive medication [29, 30]. Morning hypertension and exaggerated morning BP surge are important and recognized risk for atherosclerotic cardiovascular disease, [31-34] and uncontrolled nocturnal hypertension is associated with residual cardiovascular event risk including heart failure [31, 35-38]. For example, in the recent Japan Ambulatory Blood Pressure Monitoring Prospective study, elevated nighttime BP was a significant independent risk factor for cardiovascular events (especially heart failure), and higher nighttime versus daytime BP ("riser" pattern) was associated with residual risk for heart failure even in patients with well-controlled hypertension [38]. Thus, it would seem reasonable to recommend RDN in addition to antihypertensive dosage adjustment.

\section{Hypertension management strategy}

The ultimate goal when treating hypertension is to suppress the vicious cycle of elevated BP and organ damage and prevent cardiovascular and/or age-related disease [39]. We suggest that RDN should be considered as part of an overall hypertension management strategy, in combination with lifestyle modification and medication. The approach taken might differ slightly depending on the patient profile and cardiovascular diseases targeted (e.g. heart failure, atrial fibrillation, and chronic kidney disease) (Fig. 2). RDN may have a role in preventing the development of hypertensive heart disease due to its beneficial effects on cardiac hypertrophy and diastolic dysfunction [40], and could also prevent atrial fibrillation [41]. Based on these effects, RDN has potential for the prevention of heart failure with preserved ejection fraction.

There are a number of newer agents for the treatment of hypertension and/or heart failure that reduce circulating blood volume and lower 24-h BP (especially nighttime BP). These include highly selective non-steroidal mineralocorticoid receptor blockers, angiotensin receptor neprilysin inhibitors (ARNI) and sodium-glucose cotransporter 2 inhibitors (SGLT2i). The sympatholytic activity of RDN decreases levels of both neprilysin and sodium-glucose cotransporter 2 [42, 43], meaning that RDN could potentially improve the efficacy of ARNI and SGLT2i.

Another new approach for hypertension management is the incorporation of digital therapeutics, which facilitate the uptake and effectiveness of non-pharmacological lifestyle interventions (e.g. reducing salt and alcohol intake, body weight and stress) [44]. Patients may have a preference for different strategies, or combination of strategies, including medication, RDN and/or digital therapeutics. In the future, as part of a shared patient-physician decision process, patient preference can be considered to develop a management approach that best meets the patient's needs and might therefore increase their adherence to therapy.

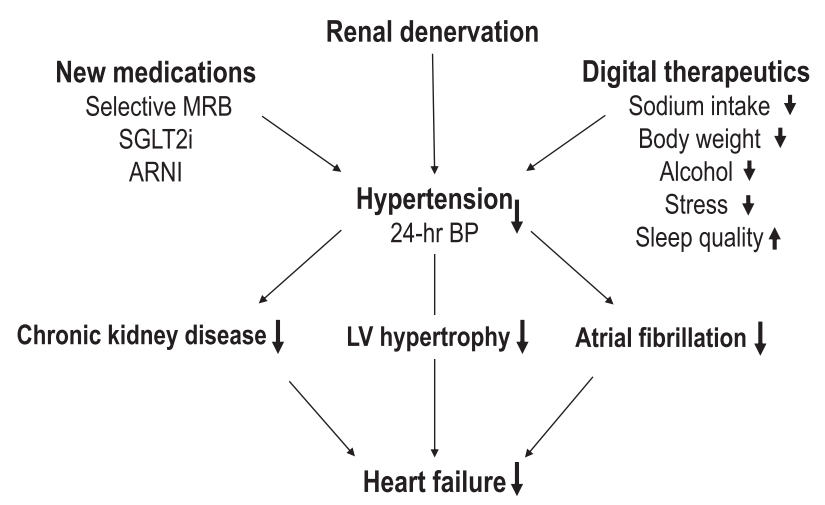

Fig. 2 Different new therapeutic approaches for hypertensive heart disease. MRB mineralcorticoid blocker, SGLT2i sodium-glucose cotransporter 2 inhibitor, ARNI angiotensin receptor neprilysin inhibitor, BP blood pressure, LV left ventricular 


\section{Conclusion and perspectives}

Uncontrolled morning hypertension and residual nocturnal hypertension despite antihypertensive pharmacotherapy are promising targets for the use of RDN in Asia. Cardiovascular diseases, including congestive heart failure, chronic kidney disease and atrial and ventricular arrhythmias, plus obstructive sleep apnea [45], are all associated with hypertension and sympathetic hyperactivity, and might therefore benefit from RDN-associated reductions in BP and circulating volume; a direct effect on sympatholytic activity on target organs is also possible.

A practical population for RDN treatment could include those of Asian ethnicity who have uncontrolled hypertension, including resistant hypertension. Inclusion of RDN in the overall hypertension management strategy has the potential to reduce the future rate and impact of hypertensive heart disease in Asia.

\section{Compliance with ethical standards}

Conflict of interest KK received speaker fees and works as a consultant to Medotronic, Co.Itd., JIMRO Co., Ltd.,Terumo Co.Itd. TDW has received honoraria from Medtronic.

Publisher's note Springer Nature remains neutral with regard to jurisdictional claims in published maps and institutional affiliations.

\section{References}

1. GBD. 2017 Risk Factor Collaborators. Global, regional, and national comparative risk assessment of 84 behavioural, environmental and occupational, and metabolic risks or clusters of risks for 195 countries and territories, 1990-2017: a systematic analysis for the Global Burden of Disease Study 2017. Lancet. 2018;392:1923-94.

2. Umemura S, Arima H, Arima S, Asayama K, Dohi Y, Hirooka Y, et al. The Japanese Society of Hypertension Guidelines for the Management of Hypertension (JSH 2019). Hypertens Res. 2019;42:1235-481.

3. Whelton PK, Carey RM, Aronow WS, Casey DE Jr, Collins KJ, Dennison Himmelfarb C, et al. 2017 ACC/AHA/AAPA/ABC/ ACPM/AGS/APhA/ASH/ASPC/NMA/PCNA guideline for the prevention, detection, evaluation, and management of high blood pressure in adults: executive summary: a report of the American College of Cardiology/American Heart Association Task Force on Clinical Practice Guidelines. J Am Coll Cardiol. 2018;71:2199-269.

4. Williams B, Mancia G, Spiering W, Agabiti Rosei E, Azizi M, Burnier M, et al. 2018 ESC/ESH Guidelines for the management of arterial hypertension. Eur Heart J. 2018;39:3021-104.

5. Katsurada K, Ogoyama Y, Imai Y, Patel KP, Kario K. New horizons in the treatment of hypertension: renal denervation based on experimental rationale. Hypertens Res. 2021 Sep 13. https:// doi.org/10.1038/s41440-021-00746-7. Online ahead of print.

6. Azizi M, Schmieder RE, Mahfoud F, Weber MA, Daemen J, Davies J, et al. Endovascular ultrasound renal denervation to treat hypertension (RADIANCE-HTN SOLO): a multicentre, international, single-blind, randomised, sham-controlled trial. Lancet. 2018;391:2335-45.

7. Kandzari DE, Böhm M, Mahfoud F, Townsend RR, Weber MA, Pocock S, et al. Effect of renal denervation on blood pressure in the presence of antihypertensive drugs: 6-month efficacy and safety results from the SPYRAL HTN-ON MED proof-of-concept randomised trial. Lancet. 2018;391:2346-55.

8. Böhm M, Kario K, Kandzari DE, Mahfoud F, Weber MA, Schmieder RE, et al. Efficacy of catheter-based renal denervation in the absence of antihypertensive medications (SPYRAL HTNOFF MED Pivotal): a multicentre, randomised, sham-controlled trial. Lancet. 2020;395:1444-51.

9. Kim BK, Kim HS, Park SJ, Park CG, Seung KB, Gwon HC, et al. Long-term outcomes after renal denervation in an Asian population: results from the Global SYMPLICITY Registry in South Korea (GSR Korea). Hypertens Res. 2021;44:1099-1104.

10. Ogoyama Y, Tada K, Abe M, Nanto S, Shibata H, Mukoyama M, et al. Effects of renal denervation on blood pressures in patients with hypertension: a systematic review and meta-analysis of randomized sham-controlled trials. Hypertens Res. 2021. https://doi.org/10.1038/s41440-021-00761-8

11. Kario K, Yokoi Y, Okamura K, Fujihara M, Ogoyama Y, Yamamoto E, et al. Catheter-based ultrasound renal denervation in patients with resistant hypertension: the randomized, controlled REQUIRE trial. Hypertens Res. 2021. https://doi.org/10.1038/ s41440-021-00754-7

12. Azizi M, Sanghvi K, Saxena M, Gosse P, Reilly JP, Levy T, et al. RADIANCE-HTN investigators. Ultrasound renal denervation for hypertension resistant to a triple medication pill (RADIANCEHTN TRIO): a randomised, multicentre, single-blind, shamcontrolled trial. Lancet 2021;397:2476-86.

13. Kario K, Kagitani H, Hayashi S, Hanamura S, Ozawa K, Kanegae H. A Japan nationwide web-based survey of patient preference for renal denervation for hypertension treatment. Hypertens Res. 2021. https://doi.org/10.1038/s41440-021-00760-9

14. Kario K, Chen CH, Park S, Park CG, Hoshide S, Cheng HM, et al. Consensus document on improving hypertension management in Asian patients, taking Into account Asian characteristics. Hypertension. 2018;71:375-82.

15. Kario K, Chia YC, Sukonthasarn A, Turana Y, Shin J, Chen CH, et al. Diversity of and initiatives for hypertension management in Asia-Why we need the HOPE Asia Network. J Clin Hypertens. 2020;22:331-43.

16. Lawes CM, Rodgers A, Bennett DA, Parag V, Suh I, Ueshima H, et al. Blood pressure and cardiovascular disease in the Asia Pacific region. J Hypertens. 2003;21:707-16.

17. Kario K, Thijs L, Staessen JA. Blood pressure measurement and treatment decisions: masked and white coat hypertension. Circ Res. 2019;124:990-1008

18. Omboni S, Aristizabal D, De la Sierra A, Dolan E, Head G, Kahan T, et al. Hypertension types defined by clinic and ambulatory blood pressure in 14143 patients referred to hypertension clinics worldwide. Data from the ARTEMIS study. J Hypertens. 2016;34:2187-98.

19. Kario K, Shimbo D, Hoshide S, Wang JG, Asayama K, Ohkubo $\mathrm{T}$, et al. The emergence of home blood pressure-guided management of hypertension based on global evidence. Hypertension. 2019;74:229-36.

20. Kario K, Kim BK, Aoki J, Wong AY, Lee YH, Wongpraparut N, et al. Renal Denervation in Asia: Consensus Statement of the Asia Renal Denervation Consortium. Hypertension. 2020;75:590-602.

21. Kario K, Ogawa H, Okumura K, Okura T, Saito S, Ueno T, et al. SYMPLICITY HTN-Japan-First Randomized Controlled Trial of Catheter-Based Renal Denervation in Asian Patients. Circ J. 2015;79:1222-9.

22. Kario K, Yamamoto E, Tomita H, Okura T, Saito S, Ueno T, et al. Sufficient and Persistent Blood Pressure Reduction in the Final 
Long-Term Results From SYMPLICITY HTN-Japan- Safety and Efficacy of Renal Denervation at 3 Years. Circ J. 2019;83:622-9.

23. Asayama K, Ohkubo T, Metoki H, Obara T, Inoue R, Kikuya M, et al. Cardiovascular outcomes in the first trial of antihypertensive therapy guided by self-measured home blood pressure. Hypertens Res. 2012;35:1102-10.

24. Hoshide S, Yano Y, Haimoto H, Yamagiwa K, Uchiba K, Nagasaka S, et al. Morning and Evening Home Blood Pressure and Risks of Incident Stroke and Coronary Artery Disease in the Japanese General Practice Population: The Japan Morning SurgeHome Blood Pressure Study. Hypertension. 2016;68:54-61.

25. Kario K, Kanegae H, Tomitani N, Okawara Y, Fujiwara T, Yano $\mathrm{Y}$, et al. Nighttime blood pressure measured by home blood pressure monitoring as an independent predictor of cardiovascular events in general practice. Hypertension. 2019;73:1240-8.

26. Mahfoud F, Böhm M, Schmieder R, Narkiewicz K, Ewen S, Ruilope L, et al. Effects of renal denervation on kidney function and long-term outcomes: 3-year follow-up from the Global SYMPLICITY Registry. Eur Heart J. 2019;40:3474-82.

27. Kim BK, Böhm M, Mahfoud F, Mancia G, Park S, Hong MK, et al. Renal denervation for treatment of uncontrolled hypertension in an Asian population: results from the Global SYMPLICITY Registry in South Korea (GSR Korea). J Hum Hypertens. 2016;30:315-21.

28. Lee CK, Wang TD, Lee YH, Fahy M, Lee CH, Sung SH, et al. Efficacy and safety of renal denervation for patients with uncontrolled hypertension in Taiwan: 3-year results from the Global SYMPLICITY Registry-Taiwan (GSR-Taiwan). Acta Cardiol Sin. 2019;35:618-26.

29. Kario K, Böhm M, Mahfoud F, Townsend RR, Weber MA, Patel $\mathrm{M}$, et al. Twenty-four-hour ambulatory blood pressure reduction patterns after renal denervation in the SPYRAL HTN-OFF MED trial. Circulation. 2018;138:1602-4.

30. Kario K, Weber MA, Mahfoud F, Kandzari DE, Schmieder RE, Kirtane AJ, et al. Changes in 24-hour patterns of blood pressure in hypertension following renal denervation therapy. Hypertension. 2019;74:244-9.

31. Kario K. Essential manual on perfect 24-hour blood pressure management from morning to nocturnal hypertension: up-to-date for anticipation medicine. Japan: Wiley Publishing Japan; 2018.

32. Hoshide S, Kario K. Morning surge in blood pressure and stroke events in a large modern ambulatory blood pressure monitoring cohort: Results of the JAMP Study. Hypertension. 2021;78:894-6.

33. Fujiwara T, Hoshide S, Kanegae H, Kario K. Clinical impact of the maximum mean value of home blood pressure on cardiovascular outcomes: a novel indicator of home blood pressure variability. Hypertension. 2021;78:840-50.

34. Narita K, Hoshide S, Kario K. Difference between morning and evening home blood pressure and cardiovascular events: the J-HOP
Study (Japan Morning Surge-Home Blood Pressure). Hypertens Res. 2021. https://doi.org/10.1038/s41440-021-00686-2.

35. Kario K, Williams B. Nocturnal hypertension and heart failure: mechanisms, evidence, and new treatments. Hypertension. 2021;78:564-77.

36. Hoshide S, Kanegae H, Kario K. Nighttime home blood pressure as a mediator of $\mathrm{N}$-terminal pro-brain natriuretic peptide in cardiovascular events. Hypertens Res. 2021;44:1138-1146.

37. Kario K, Hoshide S, Nagai M, Okawara Y, Kanegae H. Sleep and Cardiovascular outcome in Relation to Nocturnal Hypertension: The J-HOP Nocturnal Blood Pressure Study. Hypertens Res. 2021 Jul. https://doi.org/10.1038/s41440-021-00709-y. Online ahead of print. PMID: 34331030.

38. Kario K, Hoshide S, Mizuno H, Kabutoya T, Nishizawa M, Yoshida T, et al. Nighttime Blood Pressure Phenotype and Cardiovascular Prognosis: Practitioner-Based Nationwide JAMP Study. Circulation. 2020;142:1810-20.

39. Kario K, Chirinos JA, Townsend RR, Weber MA, Scuteri A, Avolio A, et al. Systemic hemodynamic atherothrombotic syndrome (SHATS) - Coupling vascular disease and blood pressure variability: Proposed concept from pulse of Asia. Prog Cardiovasc Dis. 2020;63:22-32.

40. Kresoja KP, Rommel KP, Fengler K, von Roeder M, Besler C, Lücke $C$, et al. Renal sympathetic denervation in patients with heart failure with preserved ejection fraction. Circ Heart Fail. 2021;14:e007421.

41. Steinberg JS, Shabanov V, Ponomarev D, Losik D, Ivanickiy E, Kropotkin E, et al. Effect of Renal Denervation and Catheter Ablation vs Catheter Ablation Alone on Atrial Fibrillation Recurrence Among Patients With Paroxysmal Atrial Fibrillation and Hypertension: The ERADICATE-AF Randomized Clinical Trial. JAMA. 2020;323:248-55.

42. Polhemus DJ, Trivedi RK, Gao J, Li Z, Scarborough AL, Goodchild TT, et al. Renal sympathetic denervation protects the failing heart via inhibition of neprilysin activity in the kidney. J Am Coll Cardiol. 2017;70:2139-53.

43. Herat LY, Magno AL, Rudnicka C, Hricova J, Carnagarin R, Ward NC, et al. SGLT2 inhibitor-induced sympathoinhibition: a novel mechanism for cardiorenal protection. JACC Basic Transl Sci. 2020;5:169-79.

44. Kario K, Nomura A, Harada N, Okura A, Nakagawa K, Tanigawa $\mathrm{T}$, et al. Efficacy of a digital therapeutics system for the management of essential hypertension (HERB-DH1 pivotal) in the absence of antihypertensive medications: the multicentre, randomised, open-label trial. Eur Heart J. 2021 Aug 29; ehab559. https://doi.org/10.1093/eurheartj/ehab559. Online ahead of print.

45. Kario K, Hettrick DA, Prejbisz A, Januszewicz A. Obstructive sleep apnea-induced neurogenic nocturnal hypertension: a potential role of renal denervation? Hypertension. 2021;77:1047-60. 